\title{
Efeito da Somatotropina Recombinante Bovina (rBST) no Desempenho de Novilhos Alimentados com Diferentes Volumosos ${ }^{1}$
}

\author{
Jane Maria Bertocco Ezequiel ${ }^{2}$, Alexandre Amstalden Moraes Sampaio ${ }^{3}$, Fernanda Pereira da \\ Silva ${ }^{4}$, Juliana Borsari Dourado Sancanari ${ }^{5}$, Marcos Macari ${ }^{6}$, Rodolfo Marques de Brito ${ }^{5}$, \\ Sérgio Nascimento Kronka ${ }^{7}$
}

\begin{abstract}
RESUMO - O efeito da somatotropina recombinante bovina (rBST) no desempenho de novilhos alimentados com rações com diferentes volumosos foi avaliado. Quarenta novilhos cruzados e castrados, com 360,2 kg PV médio e 30 meses de idade, foram usados. Os animais foram alimentados com rações contendo diferentes volumosos (silagem de milho, cana-de-açúcar, silagem de milho + canade-açúcar e bagaço de cana hidrolisado) e receberam aplicação de $320 \mathrm{mg} \mathrm{rBST}$ a cada 28 dias e foram pesados a cada 14 dias durante um periodo experimental de 84 dias. Ganho de peso, consumo de matéria seca e proteína bruta por kg de ganho de peso e conversão alimentar, foram avaliados. Não houve diferença no ganho de peso entre os animais que receberam $(1,210 \mathrm{~kg} / \mathrm{cab} \bullet$ dia $)$ ou não $(1,062 \mathrm{~kg} / \mathrm{cab} \bullet$ dia) rBST, apesar de os animais que receberam rBST terem apresentado maior ganho de peso nos períodos após a segunda e terceira aplicação. Não houve, também, diferença entre as rações contendo silagem de milho (1,100 kg/cab·dia), cana-de-açúcar (1,240 kg/cab·dia), cana+silagem $(1,064 \mathrm{~kg} / \mathrm{cab} \bullet$ dia) e bagaço hidrolisado (1,138 kg/cab•dia). A conversão alimentar foi 9,43 e 9,69 kg MS/ $\mathrm{kg}$ de ganho de peso para os animais que receberam ou não rBST, respectivamente. O consumo de proteína bruta reduziu com a aplicação de rBST e foi mais expressivo na ração contendo cana-de-açúcar. Não houve interação entre a aplicação do hormônio e o tipo de volumoso.
\end{abstract}

Palavras-chave: bagaço hidrolisado, bovinos de corte, cana-de-açúcar, confinamento, desempenho, silagem de milho, somatrotopina bovina

\section{Effect of Recombinant Bovine Somatotropin (rBST) on the Performance of Steers Fed Different Forages}

\begin{abstract}
Effect of recombinant bovine somatotropin (rBST) on the performance of steers fed diets with different forages was evaluated. Forty crossbred steers, with average $360.2 \mathrm{~kg} \mathrm{LW}$ and 30 months of age, were used. The animals were fed diets containing different forages (corn silage, sugarcane, corn silage + sugarcane and hydrolyzed sugarcane bagasse), and received an application of $320 \mathrm{mg}$ rBST at every 28 days and were weighed at every 14 days during an experimental period of 84 days. The weight gain, dry matter and protein per $\mathrm{kg}$ of weight gain and feed:gain ratio were evaluated. There were no differences on the weight gain among the animals that received $(1.210 \mathrm{~kg} / \mathrm{head} \bullet \mathrm{d})$ or not $(1.062 \mathrm{~kg} / \mathrm{head} \cdot \mathrm{d}) \mathrm{rBST}$, although the animals that received $\mathrm{rBST}$ had higher weight gain in the periods after the second and third hormone application. There were, also, no differences among the diets containing corn silage $(1.100 \mathrm{~kg} / \mathrm{head} \bullet \mathrm{d})$, sugarcane $(1.240 \mathrm{~kg} / \mathrm{head} \bullet \mathrm{d})$, corn silage + sugarcane $(1.064 \mathrm{~kg} / \mathrm{head} \bullet \mathrm{d})$ and sugarcane bagasse $(1.138 \mathrm{~kg} /$ head•d). The feed:gain ratios were 9.43 and $9.69 \mathrm{~kg} \mathrm{MS} / \mathrm{kg}$ of weight gain for the animals that receiving and not receiving $\mathrm{rBST}$, respectively. The crude protein intake decreased with the rBST application and was more expressive in the diet containing sugarcane. There was no interaction between the hormone application and the forage type.
\end{abstract}

Key Words: hydrolyzed bagasse, beef cattle, sugarcane, feedlot, performance, corn silage, bovine somatotropin

\section{Introdução}

O confinamento de gado de corte representa alternativa para se otimizar a produção de carne no período do ano em que há escassez de forragens. No entanto, para que esta atividade seja economicamente viável, é preciso explorar as várias técnicas disponíveis, como cruzamento entre raças, produção e conservação de forragens de alta qualidade, utilização de aditivos e adequação das dietas, visando conciliar o melhor desempenho a menor custo de produção.

Os estudos de controle do desenvolvimento dos

${ }_{1}^{1}$ Pesquisa financiada pela FAPESP.

2 Zootecnista, Prof. Dr. do Dept ${ }^{\circ}$ de Zootecnia (DZ) - Fac. Ciências Agrárias e Veterinárias (FCAV)/Unesp, Rod. Carlos Tonnani km 5, CEP 14870000, Jaboticabal (SP).

3 Zootecnista, Prof. Adjunto do DZ - FCAVJ/Unesp. Bolsista do CNPq. e-mail: sampaio@fcav.unesp.br

4 Zootecnista/FCAVJ/UNESP.

5 Zootecnista, Pós-graduando em Zootecnia na FCAVJ/UNESP.

${ }^{6}$ Biólogo, Prof. Titular do Depto. de Fisiologia Animal - FCAVJ/UNESP.

7 Estatístico, Prof. Titular do Depto. de Ciências Exatas - FCAVJ/UNESP. 
animais têm envolvido aplicação de aditivos como hormônios protéicos, antibióticos, anabolizantes, ionóforos e suas implicações no metabolismo e na performance geral do animal. A somatotropina bovina (BST) é um aditivo recentemente utilizado que acarreta efeitos como incremento da divisão celular, o metabolismo de carboidratos e lipídios, além da galactopoiese. Essas alterações ocorrem por meio de ação direta do BST em alguns tecidos (figado e tecido adiposo) e indiretamente na indução do aumento no fator 1 de crescimento (IGF-1) em tecidos como glândulas mamárias, músculo e ossos (CROOKER e OTTERBY, 1991). Em bovinos em crescimento, a retenção de nitrogênio $(\mathrm{N})$ é aumentada durante o tratamento com BST, sendo observada relação linear positiva entre o nível sérico de IGF-1 e a retenção de N (CROOKER et al., 1990).

$\mathrm{O}$ aumento no ganho de peso e a melhora na conversão alimentar foram verificados por EARLY et al. (1990), tratando novilhos com 20,6 mg/cab•dia de rBST (análogo do BST, obtido comercialmente pela técnica do DNA recombinante). Esses autores verificaram aumento significativo $(\mathrm{P}<0,01)$ de $15 \%$ no ganho de peso e melhora de $12 \%$ na conversão alimentar no início do período experimental.

Com o objetivo de determinar a dose resposta da rBST sobre o desempenho no crescimento, DALKE et al. (1992) implantaram doses semanais de 0, 40, 80 e $160 \mathrm{mg} / \mathrm{cab}$ de rBST em 120 novilhos cruzados. O tratamento hormonal reduziu a ingestão de matéria seca $(\mathrm{P}<0,10)$ e melhorou a conversão alimentar $(\mathrm{P}<0,05)$, à medida que as doses foram aumentadas, porém não influiu no ganho de peso obtido em cada tratamento. SCHWARZ et al. (1993), trabalhando com novilhas para corte, detectaram que a utilização de injeções subcutâneas de rBST em duas doses (320 e $640 \mathrm{mg} / \mathrm{cab}$ ), a intervalos de 14 dias não influenciou o ganho médio diário, havendo tendência de aumento para novilhas tratadas em relação às não tratadas.

A insuficiência das pastagens no inverno força os pecuaristas e técnicos a buscar alimentos alternativos, especialmente volumosos, que propiciem a manutenção do nível de produção dos animais, principalmente nos modelos de produção em que se utiliza o confinamento nesta época do ano. A cana-de-açúcar é uma cultura tradicional, de grande produção por unidade de área exatamente na entressafra agrícola. Porém, este alimento apresenta algumas limitações como o alto teor de açúcares e fibras, respectivamente de alta e baixa degradabilidade ruminal, a ausência de amido, o reduzido teor protéico e de minerais
(PEREIRA et al., 1996), o que evidencia a necessidade de buscar complementos que otimizem sua utilização pelo animal, que poderá ser melhorado pelo uso de aditivos de ação ruminal ou tissular.

O bagaço de cana-de-açúcar é o principal subproduto desta gramínea, produzido em grandes quantidades e considerado fonte razoável de volumoso para o gado, principalmente se houver ruptura da lignina por ação de altas temperaturas, elevadas pressões ou ação química de alcalis. EZEQUIEL (1980) e PACOLA et al. (1984) testaram o bagaço in natura e não conseguiram resultados satisfatórios. A hidrólise sofrida por este material rompe as ligações ligno-celulósicas e altera a fração hemicelulose, tornando-o mais nutritivo (VITTI et al., 1985). Mesmo assim, a utilização do bagaço hidrolisado necessita de suplementação com concentrados em quantidades variadas para diferentes níveis de produção animal.

A silagem de milho é um alimento de alto potencial para promover melhores ganhos de peso e possui moderada energia e baixo teor protéico (SHIRLEY, 1986), com boas respostas à suplementação protéica, merecendo atenção especial por parte dos estudos com gado confinado, como mostraram OBEID et al. (1980), CODAGNONE et al. (1988) e ROSTON (1990).

Assim, foi objetivo deste trabalho avaliar o desempenho de bovinos confinados com rações compostas por diferentes volumosos e tratados ou não com rBST.

\section{Material e Métodos}

O trabalho foi conduzido no setor de Bovinocultura de Corte da FCAVJ/UNESP, onde foram utilizados 40 novilhos cruzados e castrados com idade de 30 meses e peso vivo médio de $360,2 \mathrm{~kg}$. Os animais receberam identificação individual, vacinas e vermífugos, foram divididos em blocos por peso e sorteados ao acaso em quatro grupos de 10 animais, sendo que cada grupo foi alojado em um curral de $480 \mathrm{~m}^{2}$ provido de bebedouros e saleiro. Antes da pesagem inicial, os animais permaneceram 14 dias em adaptação ao local e às dietas.

Foram utilizados três volumosos para composição de quatro rações experimentais assim compostas: silagem de milho, cana-de-açúcar (variedade CO413), silagem de milho + cana-de-açúcar e bagaço de cana-de-açúcar auto-hidrolisado. A ração composta por bagaço hidrolisado continha $12 \%$ da matéria seca em cana-deaçúcar para correção dos teores de fibra longa (GARCIA e ROSSEL, 1987). O concentrado foi composto por milho e soja integral triturados, além de mistura mineral completa, visando atender as exigências de crescimento 
Rev. bras. zootec.

Tabela 1 - Proporção dos ingredientes e teores de matéria seca (MS) e proteína bruta (PB) das dietas experimentais no ajuste inicial (\%MS)

Table 1 - Proportion of ingredients and dry matter (DM) and crude protein (CP) contents of experimental diets in initial adjustment (\%MS)

\begin{tabular}{lcccc}
\hline $\begin{array}{l}\text { Ingrediente } \\
\text { Ingredient }\end{array}$ & $\begin{array}{c}\text { Silagem de milho } \\
\text { Corn silage }\end{array}$ & $\begin{array}{c}\text { Cana-de-açúcar } \\
\text { Sugarcane }\end{array}$ & $\begin{array}{c}\text { Silagem+Cana } \\
\text { Corn silage+Sugarcane }\end{array}$ & $\begin{array}{c}\text { Bagaço de cana } \\
\text { Sugarcane bagasse }\end{array}$ \\
$\begin{array}{l}\text { Silagem demilho } \\
\text { Corn silage }\end{array}$ & 83,8 & - & 35,1 & - \\
$\begin{array}{l}\text { Cana-de-açúcar } \\
\text { Sugarcane }\end{array}$ & - & 78,6 & 47,9 & 14,8 \\
$\begin{array}{l}\text { Bagaço de cana } \\
\text { Sugarcane bagasse }\end{array}$ & - & - & - & 58,0 \\
$\begin{array}{l}\text { Milho grão } \\
\text { Corn grain }\end{array}$ & 6,0 & 11,8 & 10,0 & 15,4 \\
$\begin{array}{l}\text { Soja integral } \\
\text { Whole soybean }\end{array}$ & 10,2 & 9,6 & 7,0 & 11,8 \\
$\begin{array}{l}\text { MS (\%) } \\
D M\end{array}$ & 37,73 & 40,38 & 37,77 & 53,16 \\
$\begin{array}{l}\text { PB }(\% \text { MS) } \\
C P(\% \text { DM) }\end{array}$ & 16,64 & 14,03 & 12,95 & 12,45 \\
\hline
\end{tabular}

e ajustando-se os requerimentos de proteína degradável segundo o ARC (1980) para ganho de peso diário de $1,2 \mathrm{~kg} / \mathrm{cab} / \mathrm{dia}$, conforme mostra a Tabela 1 . O balanceamento inicial foi reajustado no $42^{\circ}$ dia experimental para proporcionar ganho de peso diário de $1,5 \mathrm{~kg} / \mathrm{cab} /$ dia, como apresentado na Tabela 2.

Houve oito tratamentos que corresponderam às combinações de rações e aplicação de $\operatorname{rBST}(4$ x 2). Para isso, cada lote de 10 animais foi subdividido aleatoriamente em dois grupos de cinco animais, de maneira que apenas um dos grupos recebeu a aplica- ção de 320 mg de rBST (SCHWARZ et al., 1993), após a pesagem inicial. A aplicação do hormônio repetiu-se a cada 28 dias e as pesagens, a cada 14 dias, sendo estas efetuadas pela manhã, após jejum de aproximadamente 15 horas.

O arraçoamento foi parcelado em dois fornecimentos diários, colocando-se primeiramente o volumoso e, em seguida, o concentrado, homogeneizandose os alimentos, a fim de reduzir a seleção pelos animais. A cana-de-açúcar era cortada e picada diariamente, momentos antes do fornecimento, para

Tabela 2 - Proporção dos ingredientes e teores de matéria seca (MS) e proteína bruta (PB) das dietas experimentais no ajuste final (\%MS)

Table 2 - Proportion of ingredients and dry matter (DM) and crude protein (CP) contents of experimental diets in final adjustment (\%DM)

\begin{tabular}{|c|c|c|c|c|}
\hline $\begin{array}{l}\text { Ingrediente } \\
\text { Ingredient }\end{array}$ & $\begin{array}{l}\text { Silagem de milho } \\
\text { Corn silage }\end{array}$ & $\begin{array}{l}\text { Cana-de-açúcar } \\
\text { Sugarcane }\end{array}$ & $\begin{array}{c}\text { Silagem+Cana } \\
\text { Corn silage }+ \text { Sugarcane }\end{array}$ & $\begin{array}{l}\text { Bagaço de cana } \\
\text { Sugarcane bagasse }\end{array}$ \\
\hline $\begin{array}{l}\text { Silagem de milho } \\
\text { Corn silage }\end{array}$ & 76,6 & - & 31,9 & - \\
\hline $\begin{array}{l}\text { Cana-de-açúcar } \\
\text { Sugarcane }\end{array}$ & - & 72,9 & 43,9 & 11,3 \\
\hline $\begin{array}{l}\text { Bagaço de cana } \\
\text { Sugarcane bagasse }\end{array}$ & - & - & - & 55,0 \\
\hline $\begin{array}{l}\text { Milho grão } \\
\text { Corn grain }\end{array}$ & 13,1 & 16,5 & 14,0 & 21,2 \\
\hline $\begin{array}{l}\text { Soja integral } \\
\text { Whole soybean }\end{array}$ & 10,3 & 10,6 & 10,2 & 12,5 \\
\hline $\begin{array}{l}\text { MS (\%) } \\
D M\end{array}$ & 42,12 & 44,25 & 41,31 & 56,73 \\
\hline $\begin{array}{l}\mathrm{PB}(\% \text { da } \mathrm{MS}) \\
C P(\% \text { of } D M)\end{array}$ & 16,35 & 14,98 & 15,22 & 13,07 \\
\hline
\end{tabular}


se evitar o processo indesejável de fermentação. O controle de consumo foi realizado diariamente, pela manhã, pesando-se e amostrando-se as sobras do dia anterior, constituindo-se amostras compostas semanais, que foram enviadas ao laboratório para análise de matéria seca e nitrogênio total (micro-Kjeldahl).

$\mathrm{O}$ modelo estatístico utilizado para avaliar o ganho de peso diário nos subperíodos foi o delineamento em blocos casualizados com parcelas subdivididas, tendo como tratamentos principais as rações contendo os diferentes volumosos $\mathrm{x}$ aplicação de rBST e como tratamento secundário os períodos de 14 dias entre cada pesagem (BANZATTO e KRONKA, 1992). A análise das variáveis de desempenho referentes ao período total de experimentação seguiu o modelo do delineamento em blocos casualizados em esquema fatorial 4 x 2 (volumosos $\mathrm{x}$ rBST). A conversão alimentar e o consumo de proteína foram expressos em estimativa da média de cada animal, já que a análise estatística não pôde ser feita, uma vez que os dados foram quantificados para o grupo de animais e não individualmente.

\section{Resultados e Discussão}

Não foi encontrado efeito da interação entre as rações compostas pelos diferentes volumosos e a aplicação de rBST, assim como não se observou diferença para o ganho de peso no período total de 84 dias de confinamento (Tabela 5). Mesmo sem diferença significativa, os dados obtidos com as diferentes rações mostram tendência de maior ganho de peso dos animais alimentados com ração contendo cana-de-açúcar, quando comparada às demais. Este resultado também é bastante satisfatório quando comparado com os resultados de CAIELLE (1975) e
ANDRADE et al. (1972), que obtiveram 0,610 e $0,360 \mathrm{~kg} / \mathrm{cab} \bullet$ dia, respectivamente, utilizando rações à base de cana-de-açúcar. Os ganhos obtidos com silagem de milho e silagem + cana foram superiores aos encontrados por OBEID et al. (1980) e MATTOS (1973) de 0,950 e 0,905 kg/cab•dia respectivamente. A ração contendo bagaço hidrolisado proporcionou ganho próximo ao obtido por BERCHIELLI et al. (1990), de 1,136 kg/cab•dia, utilizando 75\% do volumoso como bagaço hidrolisado.

O efeito da aplicação de rBST sobre o ganho de peso, apresentado na Tabela 5, não proporcionou diferença entre os animais tratados e não-tratados. Este resultado está de acordo com DALKE et al. (1992) e SCHWARZ et al. (1993), que obtiveram maior média para animais tratados, porém sem diferenças significativas em relação aos animais não tratados. Em contraste aos resultados obtidos aqui, EARLY et al. (1990) e MOSELEY et al. (1992) observaram efeito significativo no ganho de peso para animais tratados com rBST, sendo estes 15 e 10,8\% superiores aos animais controle, respectivamente. Os primeiros autores atribuíram as diferenças ao crescimento dos componentes viscerais, pois o peso de carcaça não sofreu alterações entre os tratamentos.

Foi detectada diferença entre os sub-períodos $(\mathrm{P}<0,01)$, havendo interação significativa entre volumosos e sub-períodos $(\mathrm{P}<0,01)$ e hormônio e subperíodos $(\mathrm{P}<0,05)$. As médias de ganho de peso obtidas nos sub-períodos para rações e aplicação de hormônio encontram-se nas Tabelas 3 e 4, respectivamente. Pode-se observar na Tabela 3 que apenas no sub-período 1 houve diferença $(\mathrm{P}<0,05)$ entre rações, destacando-se a ração com cana-de-açúcar, com média $29 \%$ superior à silagem e silagem+cana e 49\% superior ao bagaço hidrolisado. Provavelmente,

Tabela 3 - Ganho médio diário em cada sub-período (14 dias), de acordo com o volumoso Table 3 - Average daily gain in each sub-period (14 days), according to the forage

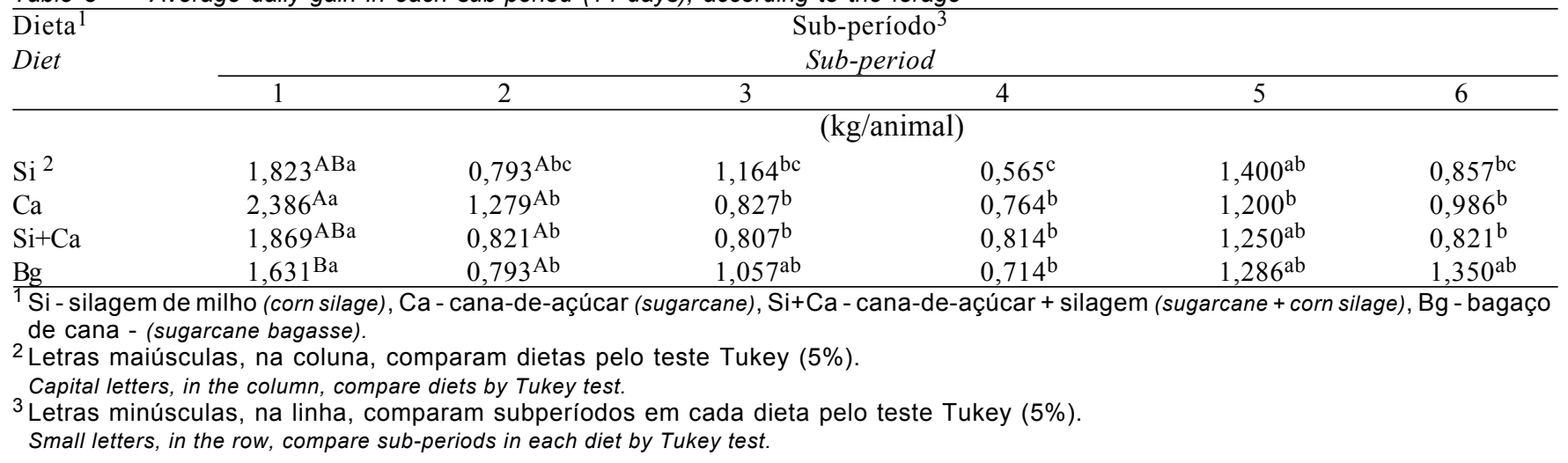


Rev. bras. zootec.

Tabela 4 - Ganho médio diário em cada sub-período (14 dias), de acordo com a aplicação de rBST Table 4 - $\quad$ Average daily gains in each sub-period (14 days), according to the rBST application

\begin{tabular}{|c|c|c|c|c|c|}
\hline \multirow[t]{2}{*}{$\mathrm{rBST}^{\mathrm{I}}$} & \multicolumn{5}{|c|}{$\begin{array}{c}\text { Sub-período }^{2} \\
\text { Sub-period }\end{array}$} \\
\hline & 1 & 2 & 3 & 4 & 5 \\
\hline Sem & $1,896^{\mathrm{a}}$ & $0,961^{b}$ & $\underset{0,725^{\mathrm{Bb}}}{\mathrm{kg} / \text { animal }}$ & $0,647^{b}$ & $1,071^{\mathrm{Bb}}$ \\
\hline $\begin{array}{l}\text { Without } \\
\text { Com } \\
\text { With }\end{array}$ & $1,958^{\mathrm{a}}$ & $0,882^{\mathrm{c}}$ & $1,204^{\mathrm{Abc}}$ & $0,782^{\mathrm{c}}$ & $1,496^{\mathrm{Ab}}$ \\
\hline
\end{tabular}

a substancial diferença tenha sofrido interferência da resposta dos animais frente ao ganho compensátorio, uma vez que os ganhos de peso, observados no início do trabalho, indicam a ocorrência deste fenômeno. Ainda na Tabela 3 é possível notar que a resposta dos animais frente aos tratamentos não foi homogênea no decorrer do período experimental, com aumento acentuado nos subperíodos 3 e 5 . No último sub-período, a ração contendo silagem de milho permitiu queda no ganho de peso, possivelmente em função de menor consumo médio de matéria seca, como apresentado na Tabela 6 .

Em relação ao tratamento hormonal, houve diferenças no ganho de peso nos sub-períodos 3 e 5, que coincidem com os períodos logo após o tratamento com rBST. O mesmo não ocorreu no sub-período 1, talvez por interferência primária do ganho compensatório. O fato nos sub-períodos 3 e 5 está de acordo

Tabela 5 - Ganho médio diário no período total (84 dias), de acordo com o volumoso ou a aplicação de rBST

Table 5 - Average daily gain in overall period (84 days) according to the forage or the rBST application

\begin{tabular}{lc}
\hline $\begin{array}{l}\text { Dieta } \\
\text { Diet }\end{array}$ & $\begin{array}{c}\text { Ganho médio diário (kg/animal) } \\
\text { Average daily gain }\end{array}$ \\
\hline $\begin{array}{l}\text { Silagem de milho } \\
\text { Corn silage }\end{array}$ & $1,100^{\mathrm{a}}$ \\
$\begin{array}{l}\text { Cana-de-açúcar } \\
\text { Sugarcane }\end{array}$ & $1,240^{\mathrm{a}}$ \\
Silagem + Cana & $1,064^{\mathrm{a}}$ \\
$\begin{array}{l}\text { Corn silage + sugarcane } \\
\text { Bagaço de cana-de-açúcar }\end{array}$ & $1,138^{\mathrm{a}}$ \\
$\begin{array}{l}\text { Sugarcane bagasse } \\
\text { rBST }\end{array}$ & \\
$\quad$ Sem & $1,062^{\mathrm{a}}$ \\
Without & $1,210^{\mathrm{a}}$ \\
Com & \\
\multicolumn{1}{l}{ With } & \\
${ }^{1}$ Letras minúsculas, na coluna, comparam dietas ou aplicação de \\
rBST pelo teste Tukey (5\%). \\
${ }^{1}$ Small letters, in the column, compare diets orrBST application by Tukeytest.
\end{tabular}

com as observações de SCHWARZ et al. (1993), que encontraram maiores concentrações de IGF-1 no sangue coletado 7 a 14 dias após a administração do hormônio. GLUCKMAN e BREIER (1989) relatam que, para haver desempenho de ganho acentuado em resposta à ação indireta da somatotropina, por meio do IGF-1, os animais devem se encontrar em balanço energético positivo.

As Tabelas 7 e 8 apresentam as médias de conversão alimentar estimadas a partir do consumo do lote de animais e dos ganhos de peso individuais. Pode-se observar que no sub-período 3 as rações contendo silagem e cana-de-açúcar proporcionaram melhora na conversão alimentar, sendo que no subperíodo 5 todos os tratamentos apresentaram o mesmo comportamento, ressaltando-se que se trata da fase pós-aplicação de rBST. Considerando a média do período total, a conversão alimentar obtida com silagem de milho esteve próxima à observada por MATTOS (1973), enquanto a ração com bagaço hidrolisado proporcionou média pior que a encontrada por BERCHIELLI et al. (1990), de 7,52 kg MS/kg GPV.

Na Tabela 8 observam-se as excelentes conversões alimentares obtidas com ambos os tratamentos no sub-período 1, certamente devido à expressão do ganho compensatório. Ao longo dos demais subperíodos, não houve destaque para nenhum dos dois grupos, excetuando-se o período 5 com menor média nos animais tratados. Considerando o período total, observou-se menor valor de conversão para o tratamento com rBST, porém a diferença em relação aos animais não tratados foi pequena. Com efeito, EARLY et al. (1990) e DALKE et al. (1992) observaram que a conversão alimentar de animais tratados com rBST foi $12 \%$ melhor que em animais não-tratados, quando administraram $160 \mathrm{mg} /$ cab•semana.

MOSELEY et al. (1992) e SCHWARZ et al. 
EZEQUIEL et al.

Tabela 6 - Consumo médio de matéria seca em cada sub-período ( 14 dias) e no período total (84 dias), de acordo com o volumoso

Table 6 - $\quad$ Average dry matter intake in each sub-period (14 days) and in overall period (84 days) according to the forage

\begin{tabular}{|c|c|c|c|c|c|c|c|}
\hline \multirow{3}{*}{$\begin{array}{l}\text { Dieta }^{1} \\
\text { Diet }\end{array}$} & \multirow{2}{*}{\multicolumn{6}{|c|}{$\begin{array}{l}\text { Sub-período }^{3} \\
\text { Sub-period }\end{array}$}} & \multirow[b]{3}{*}{$\begin{array}{l}\text { Período total } \\
\text { Overall period }\end{array}$} \\
\hline & & & & & & & \\
\hline & 1 & 2 & 3 & 4 & 5 & 6 & \\
\hline$\overline{\mathrm{Si}^{2}}$ & 8,65 & 8,40 & 8,96 & 9,91 & 10,38 & 9,65 & 9,32 \\
\hline $\mathrm{Ca}$ & 8,42 & 9,04 & 9,88 & 10,92 & 10,88 & 10,65 & 9,96 \\
\hline $\mathrm{Si}+\mathrm{Ca}$ & 8,76 & 8,80 & 9,58 & 11,11 & 11,08 & 10,66 & 10,00 \\
\hline $\mathrm{Bg}$ & 9,85 & 11,28 & 10,73 & 12,23 & 12,19 & 12,34 & 11,43 \\
\hline
\end{tabular}

'Si - silagem de milho (corn silag), Ca - cana-de-açúcar (sugarcane), Si+Ca - cana-de-açúcar + silagem (sugarcane + corn silage), $\mathrm{Bg}$ - bagaço de cana (sugarcane bagasse).

Tabela 7 - Conversão alimentar média em cada sub-período (14 dias) e no período total (84 dias) de acordo com o volumoso

Table 7 - Average feed:gain ratio in each sub-period (14 days) and in overall period (84 days), according to the forage

\begin{tabular}{|c|c|c|c|c|c|c|c|}
\hline \multirow{3}{*}{$\begin{array}{l}\text { Dieta } \\
\text { Diet }\end{array}$} & \multirow{2}{*}{\multicolumn{6}{|c|}{$\begin{array}{l}\text { Sub-período }^{3} \\
\text { Sub-period }\end{array}$}} & \multirow[b]{3}{*}{$\begin{array}{l}\text { Período total } \\
\text { Overall period }\end{array}$} \\
\hline & & & & & & & \\
\hline & 1 & 2 & 3 & 4 & 5 & 6 & \\
\hline $\mathrm{Si}$ & 6,78 & 11,00 & 7,80 & 14,15 & 8,80 & 9,85 & 9,73 \\
\hline $\mathrm{Ca}$ & 4,75 & 10,75 & 9,93 & 10,80 & 11,95 & 11,87 & 10,08 \\
\hline $\mathrm{Si}+\mathrm{Ca}$ & 6,95 & 11,00 & 11,50 & 11,90 & 10,00 & 11,40 & 10,46 \\
\hline $\mathrm{Bg}$ & 7,75 & 10,60 & 11,75 & 12,70 & 9,90 & 9,94 & 10,44 \\
\hline
\end{tabular}

${ }^{1} \mathrm{Si}$ - silagem de milho (corn silage), Ca - cana-de-açúcar (sugarcane), Si+Ca - cana-de-açúcar + silagem (sugarcane + corn silage), $\mathrm{Bg}$ - bagaço de cana (sugarcane bagasse).

Tabela 8 - Conversão alimentar média em cada sub-período (14 dias) e no período total (84 dias), de acordo com a aplicação de rBST

Table 8 - $\quad$ Average feed :gain ratio in each sub-period (14 days) and in overall period (84 days), according to the rBST application

\begin{tabular}{|c|c|c|c|c|c|c|c|}
\hline \multirow[t]{2}{*}{ rBST } & \multicolumn{6}{|c|}{$\begin{array}{c}\text { Sub-período }^{3} \\
\text { Sub-period }\end{array}$} & \multirow[b]{2}{*}{$\begin{array}{l}\text { Período total } \\
\text { Overall period }\end{array}$} \\
\hline & 1 & 2 & 3 & 4 & 5 & 6 & \\
\hline $\begin{array}{l}\text { Sem } \\
\text { Without }\end{array}$ & 5,32 & 9,50 & 9,46 & 12,62 & 10,58 & 10,68 & 9,69 \\
\hline $\begin{array}{l}\text { Com } \\
\text { With }\end{array}$ & 5,59 & 10,57 & 9,37 & 12,68 & 8,19 & 10,25 & 9,43 \\
\hline
\end{tabular}

(1993) observaram que a ingestão de matéria seca, bem como os resultados de conversão alimentar, aumentaram e pioraram, respectivamente, quando foram administradas doses mais elevadas de rBST. Nem sempre o efeito do hormônio foi positivo sobre a conversão alimentar, pois, segundo PETERS (1986), houve aumento de $4 \%$ quando os animais receberam rBST.

É possível notar que a literatura apresenta substanciais variações nas respostas ao efeito da administração de rBST, levando a crer que condi- ções de manejo, a dosagem, a freqüência e a rota de administração (intramuscular e sub-cutânea), a dieta, o sexo, a idade e o tipo dos animais influem nos mecanismos de ação da somatotropina.

A Tabela 9 apresenta os dados de consumo de proteína bruta, ficando evidenciada a ação hormonal frente ao ocorrido nos sub-períodos $3 \mathrm{e}$ 5 , após o tratamento com rBST, sendo que a ração contendo cana-de-açúcar foi a que mais expressou esse diferencial. 
Rev. bras. zootec.

Tabela 9 - Consumo médio de proteína bruta (kg PB/kg GPV), de acordo com o volumoso e a aplicação de rBST em cada sub-período

Table 9 - Average intake of crude protein per kilogram of LW gain ( $\mathrm{kg} C P / \mathrm{kg} L W G$ ), according to the forage and the rBST application in each sub-period

\begin{tabular}{lccccccc}
\hline rBST & Dieta $(\text { Diet })^{1}$ & \multicolumn{7}{c}{ Sub-período (Sub-period) $^{3}$} \\
\cline { 3 - 7 } & & 1 & 2 & 3 & 4 & 5 & 6 \\
\hline \multirow{3}{*}{ Sem } & $\mathrm{Si}$ & 0,93 & 1,51 & 1,32 & 1,14 & 2,08 & 1,58 \\
Without & $\mathrm{Ca}$ & 0,57 & 0,74 & 1,69 & 1,61 & 2,06 & 1,48 \\
& $\mathrm{Si}+\mathrm{Ca}$ & 0,65 & 1,27 & 1,15 & 1,67 & 1,82 & 1,87 \\
& $\mathrm{Bg}$ & 0,60 & 1,15 & 1,17 & 1,50 & 1,82 & 1,21 \\
\hline \multirow{2}{*}{ Com } & $\mathrm{Si}$ & 0,71 & 1,82 & 1,14 & 1,09 & 2,43 & 1,99 \\
With & $\mathrm{Ca}$ & 0,45 & 0,91 & 1,01 & 1,36 & 1,83 & 1,62 \\
& $\mathrm{Si}+\mathrm{Ca}$ & 0,59 & 1,37 & 1,25 & 1,08 & 1,89 & 1,94 \\
& $\mathrm{Bg}$ & 0,99 & 1,31 & 1,17 & 1,20 & 1,72 & 1,24 \\
\hline
\end{tabular}

${ }^{1} \mathrm{Si}$ - silagem de milho (corn silage), Ca - cana-de-açúcar (sugarcane), Si+Ca - cana-de-açúcar + silagem (sugarcane + corn silage), $\mathrm{Bg}$ - bagaço de cana (sugarcane bagasse).

\section{Conclusões}

No presente trabalho, foi possível concluir que a administração de $320 \mathrm{mg}$ de rBST melhorou o ganho de peso de novilhos confinados apenas nos períodos imediatamente após a aplicação, não havendo efeito para o período total de confinamento. Não houve efeito dos diferentes volumosos sobre o desempenho dos animais para o período total de engorda.

\section{Referências Bibliográficas}

AGRICULTURAL AND RESEARCH COUNCIL - ARC. 1980. The nutrient requirements of farm livestock. Wallingford: CAB INTERNATIONAL. 350p.

ANDRADE, V.J. 1972. Comparação entre a uréia e o farelo de algodão como suplementos protéicos para o crescimento de bezerros azebuados na seca. Arq. Esc. Vet., 24(3):257-63.

BANZATTO, D.A., KRONKA, S.N. 1992. Experimentação agricola. 2.ed., Jaboticabal: FUNEP. 247p.

BERCHIELLI, T.T. ANDRADE, P., RIBEIRO, M.V. et al. 1990. Utilização do bagaço de cana hidrolisado e resíduo de amendoim na engorda de bovinos em confinamento. $R$. Soc. Bras. Zootec., 19:2, p.113-7.

CAIELLE, R.L. 1975. Engorda de novilhos com cana-de-açúcar, capim-elefante e concentrados. Bol. Ind. Anim., 32(1):29-36.

CODAGNONE, H.C.V., CARDOSO, R.M., CASTRO, A.C.G. et al. 1988. Silagem de milho e feno de aveia (Avena bizantina L.) na alimentação de vacas em lactação. R. Soc. Bras. Zootec., 17(6):487-97.

CROOKER, B.A., McGUIRE, M.A., COHICK, W.S. et al. 1990. Effect of dose of bovine somatotropin on nutrient utilization in growing dairy heifers. J. Nutr., 120(10):1256.

CROOKER, B.A., OTTERBY, D.E. 1991. Management of the dairy herd treated with bovine somatotropin. Vet. Clin. North Am. Food Anim. Pract., 7(2):417-37.

DALKE, B.S., ROEDER, R.A., KASSER, T.R. et al. 1992. Doseresponse effects of recombinant bovine somatotropin implants on feedlot performance in steers. J. Anim. Sci., 70(7):2130-7.

EARLY, R.J., McBRIDE, B.W., BALL, R.O.1990. Growth and metabolism in somatotropin treate steers. I - Growth serum chemistry and carcass weigth. J. Anim. Sci., 68(12):4134-43.

EZEQUIEL, J.M.B. Valor nutritivo de rações contendo diferentes proporções de bagaço de cana-de-açúcar (Saccharum spp), palha de arroz (Oriza sativa), feno de capim colonião (Panicum maximum) e feno de estrela (Cynodon plectostachyus). Jaboticabal, 1980. 110p. Dissertação (Mestrado em Zootecnia) - Faculdade de Ciências Agrárias e Veterinárias - Univesidade Estadual Paulista, 1980.

GARCIA, V.D., ROSSEL, C.E.V. 1987. Auto-hidrólise (BAH) visando ao preparo de rações para bovinos. II - Dados complementares do processo e avaliação do valor nutritivo do BAH. Bol. Téc. Coopersucar, 39:3-7.

GLUCKMAN, P.D., BREIER, B.H., PEEL, C.J. et al. Bovine somatotropin: mechanism of action and experimental results from different world ares. In: MEETING THE CHALLENGES OF NEW TECHNOLOGY, 1989. Syracuse. Proceedings... Syracuse, 1989, p.17.

MATTOS, J.C.A. 1973. Estudo comparativo entre silagem de milho e a planta seca e desintegrada (hastes, folhas e espigas) na recria e engorda em confinamento de bovinos de corte. Bol. Ind. Anim., 30(1):17-49.

MOSELEY, W.M., PAULISSEN, J.B., GOODWIN, M.C. et al. 1992. Recombinant bovine somatotropin improves growth performance in finishing beef steers. J. Anim. Sci., 70(2):412-25.

OBEID, J.A., GOMIDE, J.A., SILA, J.F.C. 1980. Efeito de níveis de uréia e do manejo de alimentação sobre o consumo alimentar e o ganho de peso de novilhos zebu em confinamento. R. Soc. Bras. Zootec., 9(3):484-92.

PACOLA, L.J., CAIELLI, E.L., MATTOS, J.C.A. 1984. Bagaço de cana-de-açúcar na engorda de bovinos confinados. Bol. Ind. Anim., 41:57-61.

PEREIRA, O.G., VALADARES FILHO, S.C., GARCIA, R. et al. 1996. Consumo e digestibilidade total e parcial dos nutrientes de dietas contendo cana-de-açúcar (Saccharum officinarum L.), sob diferentes formas, em bovinos. R. Soc. Bras. Zootec., 25(4):750-62.

PETERS, J.P. 1986. Consequences of accelerated gain and growth hormone administration for lipide metabolism in growing beef steers. J. Nutr., 116(12):2490.

ROSTON, A.D. Alimentos para ruminantes: composição bromatológica, valor nutritivo, desempenho animal. Jaboticabal, 1990. 121p. Tese (Doutorado em Zootecnia) Faculdade de Ciências Agrárias e Veterinárias - Universidade Estadual Paulista, 1990.

SCHWARZ, F.J., SCHAMS, D., ROPKE, R. et al. 1993. Effects of somatotropin treatment on growth performance, carcass traits and the endocrine system in finishing beef heifers. $J$. Anim. Sci., 71(10):2721-31.

SHIRLEY, R.L. 1986. Corn silage in nitrogen and energy nutrition of ruminants. Flórida: Academic Press. 177p.

VITTI, D.M.S., ABDALLA, A.L., LOBÃO, A.O. et al.1985. Tratamento químico, físico e biológico do bagaço de cana-deaçúcar. Com. Cient. Fac. Med. Vet. Zootec. USP, 9(2):139-42.

Recebido em: 22/10/97

Aceito em: 14/12/98 